\title{
Effect of Salicylic Acid on Mycelial Growth and Conidial Germination of Two Isolates of Fusarium mangiferae
}

\author{
Vinai Kumar* and Gurdeep Bains
}

\author{
Department of Plant Physiology, College of Basic Sciences \& Humanities, GBPUA\&T, \\ Pantnagar, Uttarakhand-263145, India \\ *Corresponding author
}

\section{A B S T R A C T}

\section{Keywords}

Mango malformation, Fusarium mangiferae, Salicylic acid

Article Info

Accepted:

24 September 2018

Available Online:

10 October 2018

\begin{abstract}
Mango malformation, a century old malady of Mangifera indica, is considered as the major constraints for mango production worldwide. Several reports claimed that Fusarium species particularly Fusarium mangiferae is associated with mango malformation. Salicylic acid is an important signaling molecule that plays crucial role in plant microbial interactions. The present study was conducted to observe in-vitro application of different concentrations of salicylic acid on mycelial growth and conidial germination of two isolates of Fusarium mangiferae. The experimental findings showed that salicylic acid inhibits mycelial growth and conidial germination of two isolates of Fusarium mangiferae more effectively at moderate to high concentrations. The inhibition of mycelial growth of both isolates of Fusarium mangiferae was found to be $\mathrm{pH}$ dependent and was more in acidic condition as compared to alkaline condition.
\end{abstract}

\section{Introduction}

Mango malformation is a most destructive, century old malady of Mangifera indica, reported first time in 1891 from Darbhanga district of Bihar, India. Now apart from India, malformation has been confirmed in most of the mango growing countries: Australia, Bangladesh, Brazil, China, Cuba, Egypt, El Salvador, Israel, Malaysia, Mexico, Myanmar, Nicaragua, Oman, Pakistan, Senegal, South Africa, Spain, Sri Lanka, Sudan, Swaziland, USA, Uganda and the United Arab Emirates (Kumar et al., 1993; Kumar et al., 2011). Although malformation does not kill the tree, the vegetative phase of the disease impedes canopy development and the floral phase reduces fruit yield dramatically (Freeman et al., 2014). In India, most of the commercially important cultivars such as Amrapali, Mallika, Neelum, Chausa, Dashehari, Bombay Green, and Langra are susceptible to this disease. It is undoubtedly a complex puzzle among scientific communities due to its annual recurrence widespread, catastrophic nature, mysterious etiology and no effective control methods (Kumar et al., 1980; Sirohi et al., 2006). Previous reports indicate that fungus species particularly Fusarium mangiferae is the cause or probable cause of mango malformation (Youssef et al., 2007; Kvas et al., 2008; Freeman et al., 2014; Joshi et al., 2014). Salicylic acid is a natural plant hormone that plays important role in plant 
microbial interactions. Previous studies have also demonstrated that exogenous application of salicylic acid has wide range of effectiveness against fungal pathogen under both in-vivo and in-vitro conditions (Wu et al., 2008; Mandal et al., 2009; Makandar et al., 2012; Qi et al., 2012). The objective of this study was to investigate the in vitro effect of salicylic acid on mycelial growth and conidial germination of two isolates of Fusarium mangiferae.

\section{Materials and Methods}

\section{Salicylic acid preparation}

Salicylic acid (SA), (GRM1476-500G) used in this experiment was purchased from Himedia laboratories (Mumbai, MH, India). The 100 $\mathrm{mM}$ stock solution was prepared by dissolving $13.81 \mathrm{~g}$ of salicylic acid in minimum volume of ethanol and then autoclaved distilled water was added to make final volume $1 \mathrm{~L}$. Different concentrations of salicylic acids solutions $(0$, $0.1,0.25,0.5,1.5,2.5,5$ and $10 \mathrm{mM}$ ) were prepared through serial dilution from stock solution. Distilled water without salicylic acid was used as the control.

\section{Isolation and identification of Fusarium mangiferae}

Ten isolates of Fusarium mangiferae were isolated from malformed tissues of different mango cultivars e.g. Amrapali, Langra, Dashehari, Bombay Green, Mallika and Chausa grown in the Experimental Mango Garden Department of Plant Physiology, GBPUA\&T, Pantnagar. The single spore culture and hyphal tip isolation techniques were used to obtain pure culture of Fusarium mangiferae as previously described procedures (Nelson et al., 1983, Britz et al., 2002, Ansari et al., 2013). Briefly, 5 mm long malformed tissues were sterilized for $2 \mathrm{~min}$ in $0.1 \% \mathrm{HgCl}_{2}$ solution and rinsed thrice with sterilized deionized water and kept on potato dextrose agar (PDA) slants/plates containing streptomycin sulfate. These slants/plates were incubated at $27^{\circ} \mathrm{C}$ in BOD incubator for 3-4 days. The identification of Fusarium isolates were done on the basis of typical macro and micro-conidia on carnation leaf agar (CLA) and presence of purple orange color on PDA media. The pure culture was maintained at $4^{0} \mathrm{C}$ on PDA medium for future use. Out of ten isolates only two isolates of Fusarium mangiferae were chosen for mycelial growth and conidial germination studies.

\section{Effects of salicylic acid on mycelial growth}

The effect of salicylic acid on the in vitro growth of Fusarium mangiferae was tested as previously described method (Qi et al., 2012). Briefly, modified spezieller nahrstoffarmer agar (SNA) media (1 g $\mathrm{KH}_{2} \mathrm{PO}_{4}, 1 \mathrm{~g} \mathrm{KNO}_{3}$, $0.5 \mathrm{~g} \mathrm{MgSO}_{4}, 0.5 \mathrm{~g} \mathrm{KCl}, 1 \mathrm{~g}$ glucose, $1 \mathrm{~g}$ sucrose, and $20 \mathrm{~g}$ agar per litre) amended with different concentrations of salicylic acid $(0$, $0.1,0.25,0.5,1.5,2.5,5$ and $10 \mathrm{mM}$ ) were prepared in sterile perti plates $(90 \mathrm{~mm}$ diameter). Each petri dish was inoculated with a $5 \mathrm{~mm}$ agar plug cut from the edge of 3-5 days old cultures obtained from the same medium. Plates with sterile water were used as control. Mycelial growth was measured for consecutive one to six days at $\mathrm{pH} 5.6$ and expressed as millimeter ( $\mathrm{mm})$.To observe effect of different $\mathrm{pH}(3.6,4.6,5.6$ and 8.0) on the mycelial growth, the $\mathrm{pH}$ of modified SNA media was adjusted with $\mathrm{HCl}$ or $\mathrm{KOH}$. All plates inoculated with isolates of Fusarium mangiferae were kept in a dark cabinet at $27^{\circ} \mathrm{C}$. The experiment was repeated two times with 3 replicates of each treatment.

\section{Effects of salicylic acid on conidial germination}

The effect of salicylic acid on conidial germination of Fusarium mangiferae was 
tested using a slight modification of previously described procedures (Wu et al., 2008; Qi et al., 2012). Briefly, $5 \mathrm{~mm}$ agar plug was taken from 7-d-old PDA culture and inoculated in potato dextrose broth (PDB) aseptically. The liquid cultures were incubated at $27^{\circ} \mathrm{C}$ with shaking at $120 \mathrm{rpm}$ for seven days. The broths were filtered through four layers of sterile cheesecloth to collect conidial suspensions. The concentration of conidia was determined by using a haemocytometer and adjusted $1 \mathrm{x} \quad 10^{6}$ conidia/ml with sterile distilled water. To study the effect on conidial germination, 100 conidia were aseptically transferred on the surface of each modified SNA plate containing different concentrations of salicylic acid. The number of germinated conidia was counted after $60 \mathrm{~h}$ of incubation at $27^{\circ} \mathrm{C}$ in the dark. Conidia were considered to have germinated if the germ tube length was equal to or greater than conidial diameter.

\section{Statistical Analysis}

The statistical analysis of data was carried out with analysis of variance for completely randomized design (CRD). Critical difference (CD) was evaluated at $5 \%$ level of significance. The means were tested at $\mathrm{P}>$ 0.05 using STPR software designed at Department of Mathematics, Statistics and Computer Science, CBSH, G.B. Pant University of Agriculture \& Technology, Pantnagar, India.

\section{Results and Discussion}

\section{Metabolite colour and growth rate}

The Fusarium mangiferae isolates exhibited different metabolite colour on potato dextrose agar (PDA). The Fm-1 isolate exhibited whitelight orange colour from upper view and white-yellow colour from lower view. The Fm-2 showed white colour from upper view and white-orange colour from lower view.
Both isolates produce macro and microconidia on carnation leaf agar. However, both isolates demonstrated different growth rate i.e. rapid and slow growth rate on PDA media. The Fm-1 exhibited rapid growth rate on PDA media whereas Fm-2 exhibited slow growth rate (Figure 1).

\section{Mycelial growth of Fusarium mangiferae isolates}

The mycelial growth of two isolates of Fusarium mangiferae was significantly influenced by different concentrations of salicylic acid on SNA media. It was observed that lower concentrations of salicylic acid (0.1 and $0.25 \mathrm{mM}$ ) promoted mycelial growth as compared to control at $\mathrm{pH}$ 5.6. In most cases, $0.5 \mathrm{mM}$ concentration of salicylic acid also promoted mycelial growth. But concentration higher than $0.5 \mathrm{mM}$ decreased mycelial growth of both the isolates of Fusarium mangiferae.

At higher concentrations of salicylic acid (5 and $10 \mathrm{mM}$ ), mycelial growth was observed very low as compared to control. Among different treatment, $0.5 \mathrm{mM}$ salicylic acid had maximum mycelial growth in Fm-1 while Fm2 exhibited highest growth in $0.25 \mathrm{mM}$ salicylic acid concentrations at 6 day (Figure 2 ). Further, the growth of mycelia seems to be $\mathrm{pH}$ dependent. Both isolates of Fusarium mangiferae exhibited more growth of mycelial after 3 days at basic $\mathrm{pH} 8.0$ as compared to acidic $\mathrm{pH}$ 5.6. However, it was observed that as the $\mathrm{pH}$ of the medium decreased the mycelial growth of both isolates also declined gradually (Figure 3 ).

\section{Conidia germination of Fusarium mangiferae isolates}

The percentage of conidia germination of two isolates of Fusarium mangiferae was tested at pH 5.6 after $60 \mathrm{~h}$ of incubation at $27{ }^{\circ} \mathrm{C}$. 
Fig.1 Colony morphology of two isolates of Fusarium mangiferae on potato dextrose agar. (A) Upper view, (B) Lower view, (C) Conidia, produced in carnation leaf agar visualized under light microscope (10X).

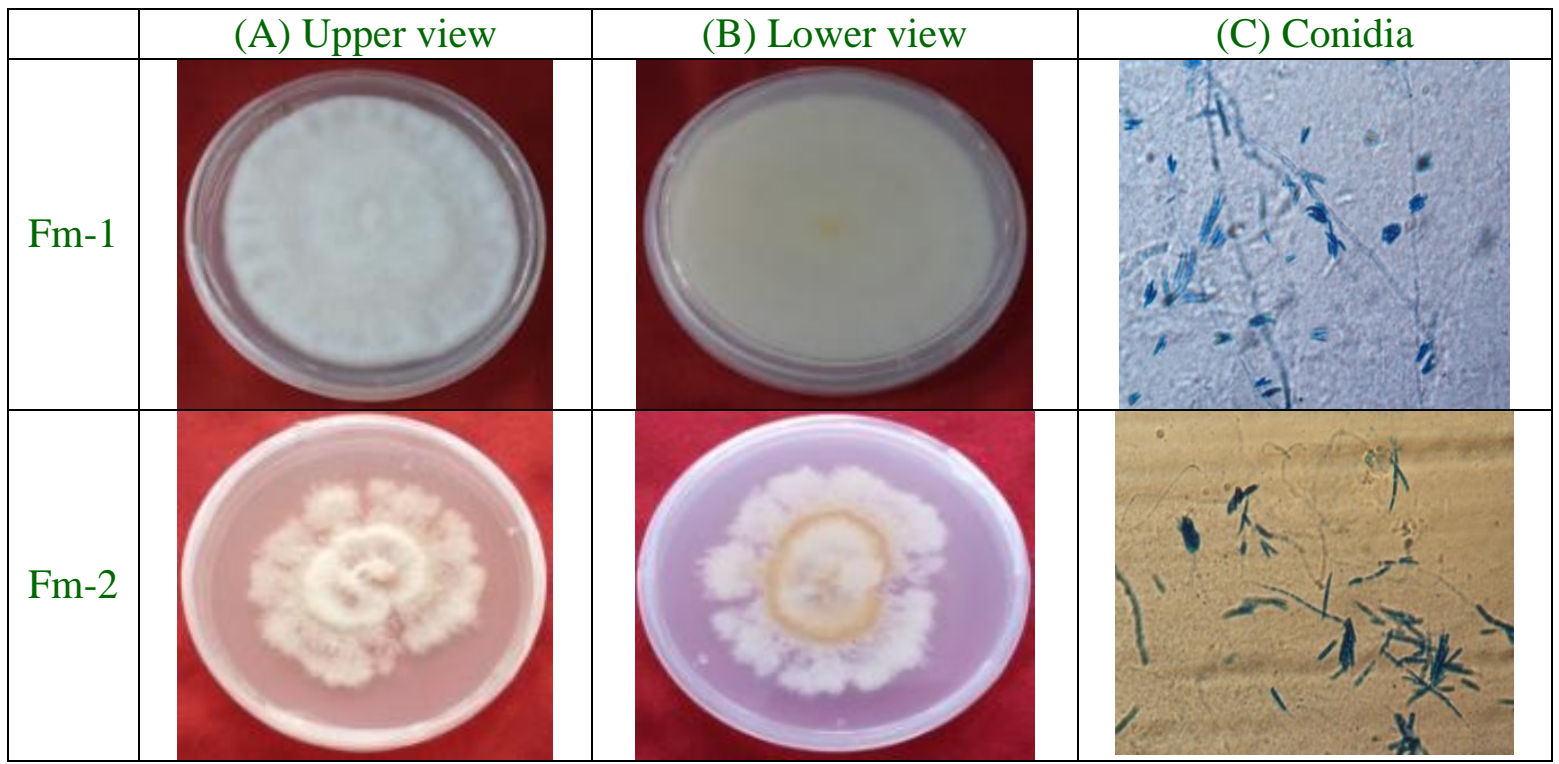

Fig.2 Effect of salicylic acid on mycelial growth of two isolates of Fusarium mangiferae (A) Fm-1, (B) Fm-2 on modified spezieller nahrstoffarmer agar (SNA) media at pH 5.6
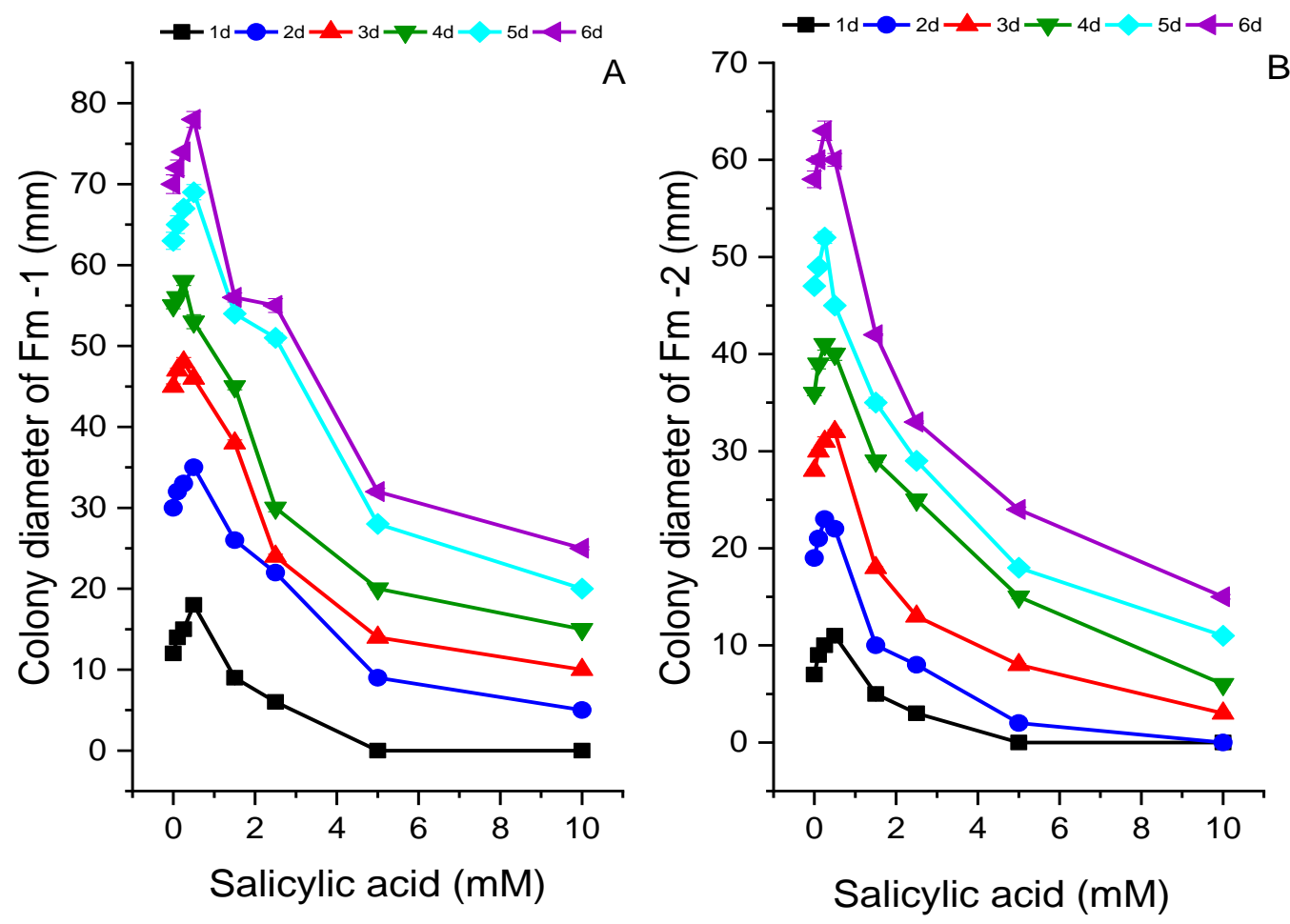
Fig.3 Effect of salicylic acid (SA) on mycelial growth of two isolates of Fusarium mangiferae (A) Fm-1, (B) Fm-2 at different $\mathrm{pH}$ on modified spezieller nahrstoffarmer agar (SNA) media
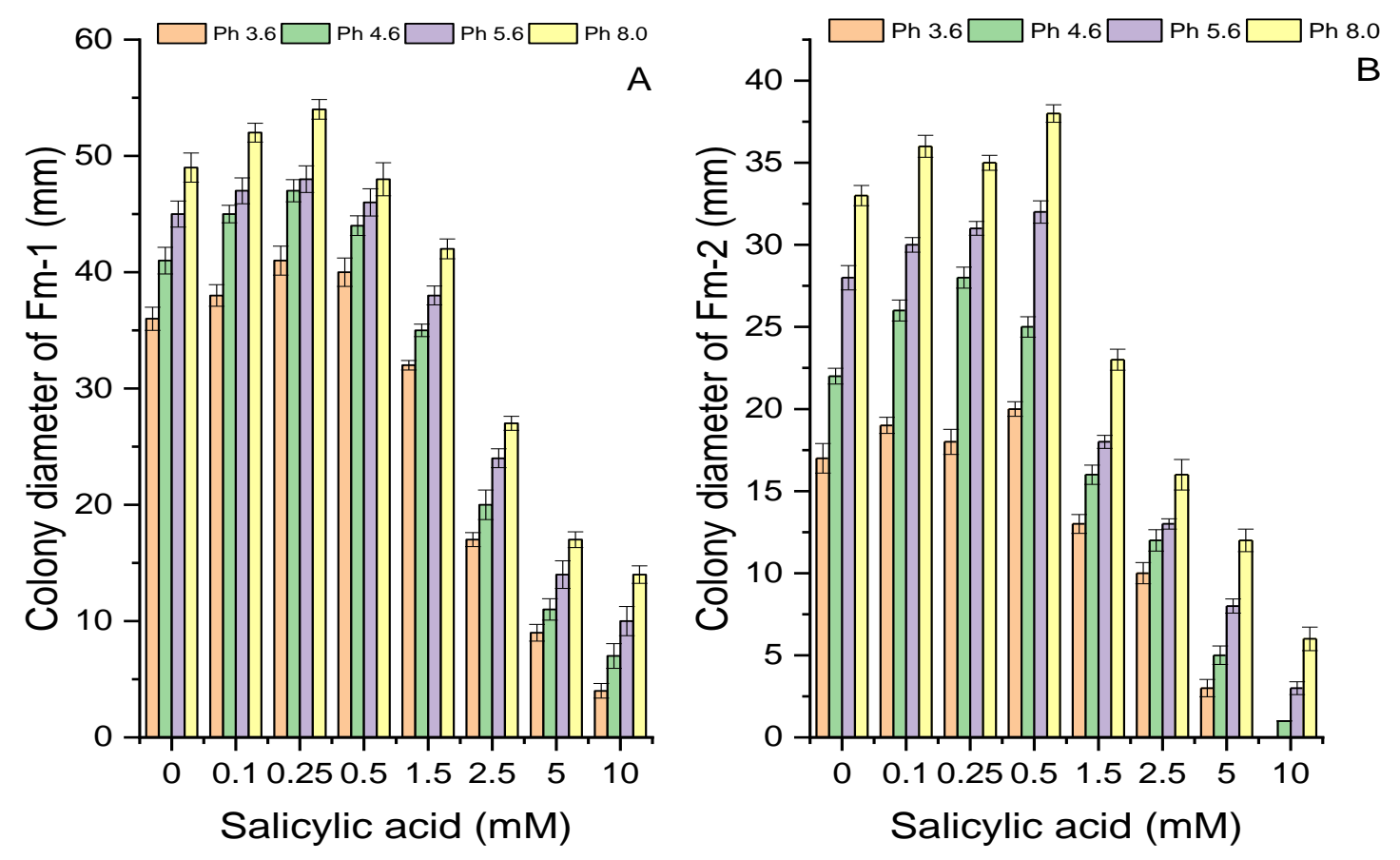

Fig.4 Effect of salicylic acid (SA) on conidia germination (\%) of two isolates of Fusarium mangiferae (Fm-1 and Fm-2) at pH 5.6 on modified spezieller nahrstoffarmer agar (SNA) media

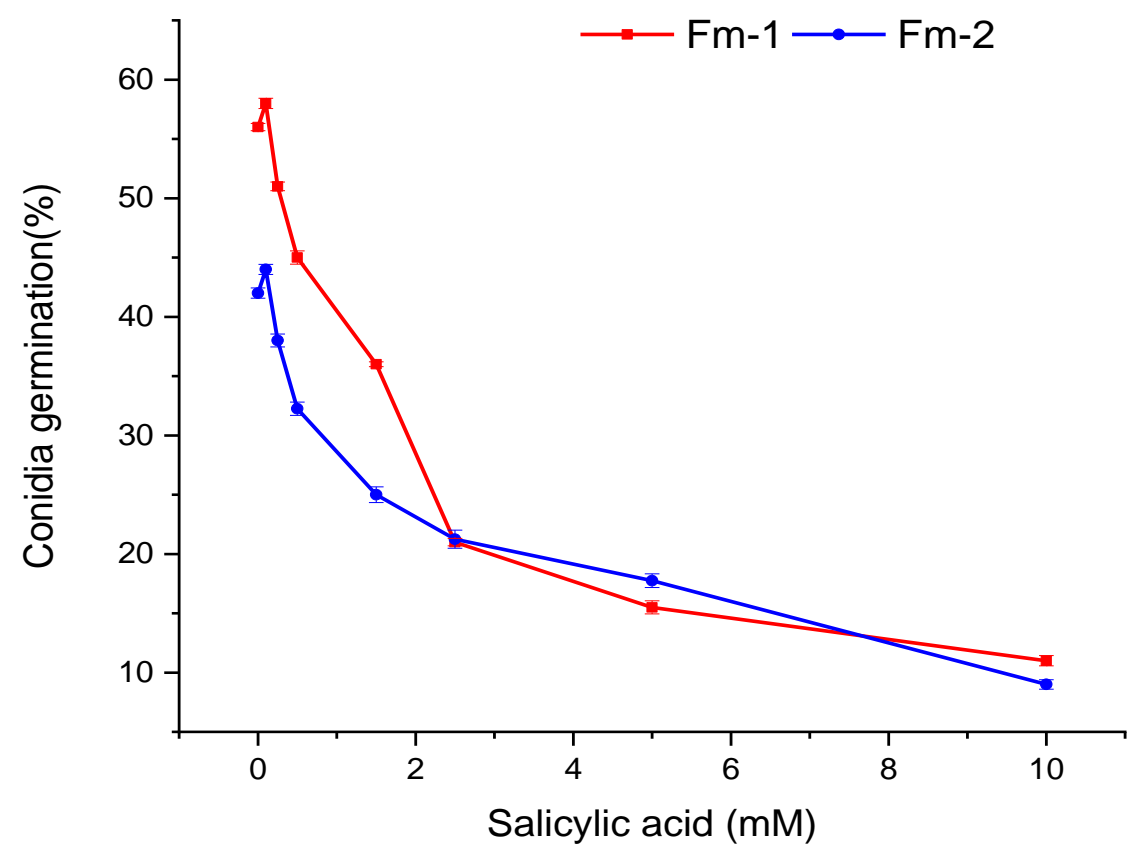


Generally, the percentage of conidia germination decreased gradually up to 0.5 $\mathrm{mM}$ salicylic acid concentration. Beyond this concentration increasing concentrations of salicylic acid causes a sharp decline in the percentage of conidia germination in both isolates of Fusarium mangiferae. However, the percentage of conidia germination varied between the isolates. The Fm-1 exhibited more percentage of conidia germination (56 $\%)$ than Fm-2 (42\%) under control condition (Figure 4).

Salicylic acid is a well-known signaling molecule that plays crucial role in plant microbial interactions (Hayat et al., 2012). It is produced naturally inside plants and its level increases many fold during various biotic and abiotic stresses. Previous studies have reported that salicylic acid contributes in plant defense response either by altering the physiology of host plants or inhibiting the growth and infection of pathogens (Chen et al., 2009; Fragnière et al., 2011). The aim of this study was to investigate in-vitro application of salicylic acid on mycelial growth and conidia germination of two isolates of Fusarium mangiferae. Our findings suggest that mycelial growth of two isolates of Fusarium mangiferae varies with different concentrations of salicylic acid and seems to be $\mathrm{pH}$ dependent.

The salicylic acid mediated mycelial growth inhibition was more pronounced at acidic $\mathrm{pH}$ than basic $\mathrm{pH}$ in both the isolates. The percentage of conidia germination in both the isolates decreased with increasing the doses of salicylic acid. This suggested that salicylic acid affects conidia germination in a dose dependent manner. The findings of our results were in accordance with $\mathrm{Wu}$ et al., 2008 and Qi et al., 2012, who also reported that in-vitro conditions exogenously applied salicylic acid inhibited mycelial growth and conidial germination of other Fusarium pathogens e.g.
Fusarium oxysporum f.sp. niveum and Fusarium graminearum respectively. Our invitro experimental finding suggests that exogenous application of salicylic acid could inhibit the infection and colonization of Fusarium mangiferae in host plant tissues and might be very helpful in controlling mango malformation.

\section{References}

Ansari, M.W., Shukla, A., Pant, R.C. and Tuteja, N., 2013. First evidence of ethylene production by Fusarium mangiferae associated with mango malformation. Plant Signaling \& Behavior. 8(1): p.e22673.

Britz, H., Steenkamp, E. T., and Coutinho, T. A. 2002. Two new species of Fusarium section Liseola associated with mango malformation. Mycologia. 94:722-730.

Chen, Z., Zheng, Z., Huang, J., Lai, Z. and Fan, B., 2009. Biosynthesis of salicylic acid in plants. Plant Signaling \& Behavior. 4(6):493-496.

Fragnière, C., Serrano, M., Abou-Mansour, E., Métraux, J.P. and L'haridon, F., 2011. Salicylic acid and its location in response to biotic and abiotic stress. FEBS letters. 585(12):1847-1852.

Freeman, S., Shtienberg, D., Maymon, M., Levin, A.G. and Ploetz, R.C., 2014. New insights into mango malformation disease epidemiology lead to a new integrated management strategy for subtropical environments. Plant Disease. 98(11):1456-1466.

Hayat, S., Irfan, M., Wani, A.S., Nasser, A. and Ahmad, A., 2012. Salicylic acids: local, systemic or inter-systemic regulators? Plant Signaling \& Behavior. 7(1):93-102.

Joshi, B., Ansari, M.W., Bains, G., Pant, R.C., Shukla, A., Tuteja, N. and Kumar, J., 2014. Fusarium mangiferae associated with mango malformation in the tarai 
region of the Uttarakhand state of India. Plant Signaling \& Behavior. 9(4): p.e22673.

Kumar, J., Beniwal, S.P.S. and Ram, S., 1980.

Depletion of auxins in mango seedlings affected with bunchy top stage of mango malformation. Indian Journal of Experimental Biology. 18: 286--289.

Kumar, J., Singh, U.S. and Beniwal, S.P.S., 1993. Mango malformation: one hundred years of research. Annual Review of Phytopathology. 31(1):217232.

Kumar, P., Misra, A.K. and Modi, D.R., 2011. Current status of mango malformation in India. Asian Journal of Plant Sciences. 10(1):1-23.

Kvas, M., Steenkamp, E.T., Al Adawi, A.O., Deadman, M.L., Al Jahwari, A.A., Marasas, W.F.O., Wingfield, B.D., Ploetz, R.C. and Wingfield, M.J., 2008. Fusarium mangiferae associated with mango malformation in the Sultanate of Oman. European Journal of Plant Pathology. 121(2):195-199.

Makandar, R., Nalam, V.J., Lee, H., Trick, H.N., Dong, Y. and Shah, J., 2012. Salicylic acid regulates basal resistance to Fusarium head blight in wheat. Molecular Plant-Microbe Interactions. 25(3):431-439.

Mandal, S., Mallick, N. and Mitra, A., 2009. Salicylic acid-induced resistance to Fusarium oxysporum f. sp. lycopersici in tomato. Plant Physiology and Biochemistry. 47(7):642-649.
Nelson PE, Toussoun TA, Marasas WFO, 1983. Fusarium Species: An Illustrated Manual for Identification. Pennsylvania, PA, USA: Pennsylvania State University Press.

Qi, P.F., Johnston, A., Balcerzak, M., Rocheleau, H., Harris, L.J., Long, X.Y., Wei, Y.M., Zheng, Y.L. and Ouellet, T., 2012. Effect of salicylic acid on Fusarium graminearum, the major causal agent of fusarium head blight in wheat. Fungal Biology. 116(3): 413426.

Sirohi, S.C., Prakash, S., Rana, P. and Singh, R. 2006. Effect of different level of shoot pruning on floral malformation in mango. Indian Journal of Hortculture. 63(3): 330-331.

Wu, H.S., Raza, W., Fan, J.Q., Sun, Y.G., Bao, W., Liu, D.Y., Huang, Q.W., Mao, Z.S., Shen, Q.R. and Miao, W.G., 2008. Antibiotic effect of exogenously applied salicylic acid on in vitro soilborne pathogen, Fusarium oxysporum f. sp. niveum. Chemosphere. 74(1): 45-50.

Youssef, S.A., Maymon, M., Zveibil, A., Klein- Gueta, D., Sztejnberg, A., Shalaby, A.A. and Freeman, S., 2007. Epidemiological aspects of mango malformation disease caused by Fusarium mangiferae and source of infection in seedlings cultivated in orchards in Egypt. Plant Pathology. 56(2):257-263.

\section{How to cite this article:}

Vinai Kumar and Gurdeep Bains. 2018. Effect of Salicylic Acid on Mycelial Growth and Conidial Germination of Two Isolates of Fusarium mangiferae. Int.J.Curr.Microbiol.App.Sci. 7(10): 3704-3710. doi: https://doi.org/10.20546/ijcmas.2018.710.428 